\title{
CARACTERIZAÇÃO IN SILICO DOS GENES ENVOLVIDOS NO METABOLISMO DO NITROGÊNIO EM MILHO (Zea mays)
}

\author{
Talita Cantú ${ }^{1}$ \\ Claudia Borsari Trevizan ${ }^{1}$ \\ Crislaine Emidio Vieira ${ }^{2}$ \\ Rafaélla David Piffer ${ }^{3}$ \\ Giovanna Carneiro Luiz ${ }^{3}$ \\ Silvia Graciele Hülse de Souza ${ }^{4}$
}

CANTÚ, T.; TREVIZAN, C. B.; VIEIRA, C. E.; PIFFER, R. D.; CARNEIRO LUIZ, G.; SOUZA, S. G. H. de. Caracterização in silico dos genes envolvidos no metabolismo do nitrogênio em milho (Zea mays). Arq. Ciênc. Vet. Zool. UNIPAR, Umuarama, v. 19, n. 4, p. 231-239, out./dez. 2016.

RESUMO: O N é o nutriente mineral requerido pelas plantas em maior quantidade e frequentemente limita o crescimento e produtividade. A partir de uma análise in silico foram identificados 26 genes envolvidos na assimilação do nitrogênio: quatro genes que codificam a enzima nitrato redutase $(Z m N R)$, oito nitrato redutase de transporte (ZmNRT), uma nitrito redutase $(Z m N R i)$, uma nitrito de transporte (ZmNRiT), seis glutamina sintetase (ZmGS), quatro glutamato sintase (ZmGOGAT) e duas glutamato desidrogenase $(Z m G D H)$. A árvore filogenética foi construída onde foi possível observar a formação de cinco grupos distintos de acordo com as funções. A análise da estrutura dos genes mostrou que o número de íntrons variou de 0 a 32. A análise dos domínios conservados mostrou que a maioria dos genes identificados possuem o domínios específicos a função que desempenham na rota de assimilação do $\mathrm{N}$ em milho. Além disso, esses genes apresentaram padrões de expressão diferenciais em tecidos e órgãos. Os dados gerados neste trabalho forneceram subsídios para selecionar genes-candidatos para futuras análises funcionais a serem utilizados nos programas de melhoramento de milho.

PALAVRAS-CHAVE: Assimilação de N. Eficiente uso do Nitrogênio. Filogenia.

\section{IN SILICO CHARACTERIZATION OF GENES INVOLVED IN NITROGEN METABOLISM IN MAIZE (Zea mays)}

\begin{abstract}
Nitrogen is a mineral highly requested by plants and often limits both growth and productivity. From an in-silico analysis, a total of 26 genes were identified as being involved in nitrogen assimilation: four genes encoding nitrate reductase enzyme $(Z m N R)$, eight encoding nitrate reductase transporters $(Z m N R T)$, one encoding nitrite reductase $(Z m N R i)$, one encoding nitrite transporter ( $Z m N R i T)$, six encoding glutamine synthesis (ZmGOGAT) and two encoding glutamate dehydrogenase $(\mathrm{ZmGDH})$. A phylogenetic tree was generated where the formation of five distinct clusters could be observed according to gene function. Structural genes analysis showed that introns varied from 0 to 32 . The analysis of conserved domains showed that most of the identified genes play a domain-specific function in the $\mathrm{N}$ assimilation pathway in maize. Moreover, these genes present a differential expression pattern in tissues and organs. Data from this study will provide subsidies to select candidate genes for further functional analyses in maize breeding programs.
\end{abstract}

KEYWORDS: Efficient use of nitrogen. N-assimilation. Phylogeny.

\section{CARACTERIZACIÓN IN SILICO DE GENES IMPLICADOS EN EL METABOLISMO DE NITRÓGENO EN MAÍZ (Zea mays)}

RESUMEN: $\mathrm{N}$ es el nutriente mineral requerido por las plantas en mayor cantidad y a menudo limita el crecimiento y la productividad. Desde un análisis in silico se ha identificado 26 genes implicados en la asimilación de nitrógeno: cuatro genes que codifican la enzima nitrato reductasa $(\mathrm{ZmNR})$, ocho nitrato reductasa de transporte (ZmNRT), un nitrito reductasa (ZmNRi), un nitrito de transporte (ZmNRiT), seis glutamina sintetasa (ZmGS), cuatro sintasa de glutamato (ZmGOGAT) y dos glutamato deshidrogenasa $(\mathrm{ZmGDH})$. El árbol filogenético se ha construido donde ha sido posible observar la formación de cinco grupos distintos de acuerdo con sus funciones. El análisis de la estructura de los genes ha mostrado que el número de intrones ha variado de 0 a 32 . El análisis de los dominios conservados mostró que la mayoría de los genes identificados poseen dominios específicos a la función que desempeñan en la ruta de asimilación de $\mathrm{N}$ en maíz. Además, esos genes mostraron patrones de expresión diferenciales en tejidos y órganos. Los datos generados en este estudio proporcionan subvenciones para la selección de genes candidatos para posterior análisis funcional, para ser utilizados en programas de mejoramiento de maíz. PALABRAS CLAVE: Asimilación de N. Filogenia. Uso eficiente del nitrógeno.

DOI: https://doi.org/10.25110/arqvet.v19i4.2016.6102

${ }^{1}$ Discente do Curso de Pós-Graduação em Biotecnologia Aplicada à Agricultura, Universidade Paranaense -UNIPAR, Umuarama, PR, 87502-210, Brasil.

${ }^{2}$ Discente do Curso de Engenharia Agronômica, Universidade Paranaense - UNIPAR, Umuarama, PR, 87502-210, Brasil.

${ }^{3}$ Discente do Curso de Farmácia, Universidade Paranaense - UNIPAR, Umuarama, PR, 87502-210, Brasil.

${ }^{4}$ Docente da Universidade Paranaense - UNIPAR, Pós-Graduação em Biotecnologia Aplicada à Agricultura, Umuarama - PR. E-mail: silviahulse@unipar.br. 


\section{Introdução}

O milho (Zea mays) é o principal cereal produzido no Brasil. Na safra 2015/2016, a área plantada dessa cultura foi de 15,7 milhões de hectares com uma produção total de 76,2 milhões de toneladas de grãos (CONAB, 2016). A sua importância econômica está diretamente relacionada às diferentes formas de utilização, seu amplo consumo na alimentação, além de ser empregado nas indústrias de tecnologia como matéria prima de filmes, embalagens biodegradáveis e bicombustíveis.

A cultura do milho requer a interação de um conjunto de fatores edafoclimáticos adequados para o seu desenvolvimento, e entre eles está o nitrogênio $(\mathrm{N})$, nutriente mineral requerido em maior quantidade pelas plantas que pode limitar o crescimento e a produtividade agrícola. Esse composto é um nutriente essencial e regulador do desenvolvimento radicular, da expansão foliar e expressão de genes de enzimas envolvidas no metabolismo do carbono e nitrogênio (WANG; VINOCUR; ALTMAN, 2003). O nitrogênio é utilizado para formar a glutamina, considerada iniciadora da síntese de diversos aminoácidos, ácidos nucléicos, enzimas e proteínas, bem como metabólitos secundários (HUANG et al., 2015). Apesar da grande quantidade de $\mathrm{N}$ na atmosfera terrestre, a maioria dos seres vivos não possui a capacidade de absorver esse elemento na forma gasosa, por isso as plantas utilizam nitrato e amônia como fonte inorgânica de nitrogênio que é absorvida pelas raízes (EPSTEIN; BLOOM, 2006).

A assimilação do nitrogênio é um processo dispendioso energeticamente às plantas, razão porque ocorre predominantemente nas folhas, centro de síntese de ATP e agentes redutores - fornecedores de elétrons (ANDRADE NETTO, 2005). O processo de incorporação do nitrogênio compete com a fotossíntese por massa e energia, consumindo 12 ATPs para cada $\mathrm{N}$ assimilado pela planta (EPSTEIN; BLOOM, 2006). A taxa e a quantidade de nitrogênio assimilada pelas plantas durante o seu ciclo dependem da atividade das enzimas envolvidas e da disponibilidade de energia necessária para os processos de assimilação (EPSTEIN; BLOOM, 2006).

O ciclo do $\mathrm{N}$ compreende os processos de redução do nitrato à amônio e a incorporação do amônio em aminoácidos, no qual a quantidade de nitrogênio assimilado pelas plantas durante o ciclo depende da atividade das enzimas envolvidas no ciclo do nitrogênio e da disponibilidade de energia (LEA, 1997). A via envolve a participação de cinco enzimas, onde existem dois sistemas de absorção de nitrato nas raízes, a alta e baixa absorção e são conhecidos como transportadores de nitrato (NRT) (BREDEMEIER; MUNDSTOCK, 2000). A nitrato redutase (NR, EC 1.6.6.1) sob o ponto de vista metabólico, é a enzima mais importante para catalisar a reação "etapa limitante" até a transformação de N inorgânico em proteína no qual o nitrato é transformado em nitrito (DEBOUBA; DGUIMI; GHORBEL, 2013). A enzima nitrito de transporte (NRiT) participa do transporte de nitrito através do citoplasma do estroma no cloroplasto (LISERON-MONFILS et al., 2013). Bastante ativa nas células, a nitrito redutase (NRi, EC 1.7.2.1) é a e enzima que transforma o nitrito em amônia. Ela é encontrada principalmente nas folhas, dentro dos cloroplastos e tilacóides, enquanto que nas raízes está localizada dentro dos plastídeos (HUANG et al., 2015).
A glutamina sintetase (GS, EC 6.3.1.2) catalisa a entrada da amônia em aminoácido por meio da conversão de ATP do glutamato em glutamina. A glutamato sintase (GOGAT, EC 1.4.1.14) é responsável pela substituição do grupo amida da glutamina para o 2-cetoglutarato utilizado para transformar duas moléculas de glutamato, e finalizando o ciclo a enzima glutamato desidrogenase (GDH, EC 1.1.1.47) está relacionada com a assimilação secundária da amônia e catalisa de forma reversível a aminação do $\alpha$-cetoglutarato (atividade aminante) e a desaminação do glutamato (atividade desaminante), envolvendo a oxidação e a redução de $\mathrm{NAD}(\mathrm{P}) \mathrm{H} /$ NAD $(\mathrm{P})^{+}$(SILVEIRA et al., 1999).

Em Arabidopsis thaliana, a nitrato redutase é codificada por dois genes NIA1 e NIA2 (DEBOUBA; DGUIMI; GHORBEL, 2013). O nitrato induz genes responsáveis pelo seu transporte (NRT1.1 e NRT2.1) e assimilação (NIA1, NIA2 e NII), mas acredita-se que o nitrato provoque mudanças na expressão de 1000 genes em $A$. thaliana (DEBOUBA; DGUIMI; GHORBEL, et al., 2013). Estudos tem sido realizados com mutantes de nitrato redutase (WANG et al., 2004), para verificar respostas moleculares ao nitrato, sugerindo uma rota de sinalização que ajusta a expressão de grande conjunto de genes responsáveis por funções fundamentais como: metabolismo celular e crescimento do organismo. A glutamina sintetase (GS) possui duas isoformas GS2 chamada glutamina sintetase plastídica e codifica um gene (GLN2) e a glutamina sintetase citocílica (GS1) que codifica cinco genes (GLN1.1 a 5 GLN1.5) (LISERON-MONFILS et al., 2013). Em A. thaliana foram identificados três genes GDH: $G D H 1, G D H 2$ e GDH3, que codificam as subunidades beta, alfa e gama da enzima, respectivamente (MARCHI et al., 2014). Entretanto, existem poucas informação dos genes que codificam as enzimas envolvidas na assimilação do nitrogênio em milho. Desta forma, com o auxílio de ferramentas computacionais e informações disponíveis nos bancos de dados esta é a primeira caracterização in silico dos genes que fazem parte do metabolismo de nitrogênio em milho.

\section{Material e Métodos}

\section{Identificação dos genes NRT, NR, NRiT, NRi, GS, GO- GAT e GDH}

Sequências protéicas das enzimas NRTe NRiT, NR, NRi, GS, GOGAT e GDH foram identificados na planta modelo arabidopsis (A. thaliana) provenientes do Banco de dados TAIR database (http://www.arabidopsis.org/). Essas sequências foram utilizadas para pesquisas no Banco de dados de Arroz (http://rice.plantbiology.msu.edu/) e no Banco de dados de Milho (http://http://www.phytozome.net/) usando a ferramenta BlastP. As sequências foram confrontadas com outras sequências depositadas no banco de dados do GenBank, utilizando os programas BlastP e BlastX (National Center for Biotechnology Information - NCBI - http://www. ncbi.nlm.nih.gov/gorf/gorf.html), para confirmar a identidade das mesmas. As sequências deduzidas de aminoácidos foram obtidas por meio do programa ORF Finder (Open Reading Frame Finder - NCBI - http://www.ncbi.nlm.nih.gov/ gorf/gorf.html). 


\section{Análise filogenética}

A análise filogenética foi realizada alinhando as sequências protéicas de arabidopsis (A. taliana - 33 sequências), arroz (Oriza sativa - 23 sequências) e milho (Z. mays 26 sequências). A árvore filogenética foi gerada utilizando-se o método Neighbor-Joining (NJ) usando a opção pair-wise deletion com o auxílio do programa MEGA versão 6.0. Para testar a confiabilidade das análises foram utilizadas 1.000 réplicas de bootstrap.

\section{Estrutura genômica}

Para a identificação da posição de íntrons e a organização de éxon/íntron nos genes foram utilizadas as sequências completas do DNA genômico e da transcrita correspondente de cada gene utilizando a ferramenta on line Gene Structure Display Server (GSDS) (http://gsds.cbi.pku.edu. $\mathrm{cn} /)$.

\section{Identificação dos motivos conservados}

A identificação dos motivos conservados foram realizadas nas sequências protéicas de $Z$. mays com o algoritmo MEME Suite versão 4.0.0 (http://meme.sdsc.edu/meme4/ cgi-bin/meme.cgi), com os seguintes parâmetros: tamanho ideal: 6-300 aminoácidos; qualquer número de repetições dos motivos e número máximo de 25 motivos. Os motivos resultantes foram verificados na base de dados do NCBI (http://www.ncbi.nlm.nih.gov/gorf/gorf.html) ExPaSy - Expert Protein Analysis System (http://ca.expasy.org/) para verificar sua significância.

Identificação dos perfis de expressão dos genes do ciclo do $\mathbf{N}$

O perfil de expressão in silico dos genes NRT, NRiT, NR, NRi, GS, GOGAT e GDH de Z. mays foram analisados em bibliotecas de tecidos específicos de diferentes fases de desenvolvimento utilizando os dados de microarranjo do banco de dados Banco de dados MaizePLEX (http://www. plexdb.org/plex.php?database $=$ corn). Os dados de expressão foram transformados $\log 2$ e o heatmap foi gerado com o algoritmo CIMMiner (http://discover.nci.nih.gov/cimminer).

\section{Resultados e Discussão}

\section{Identificação dos genes no metabolismo do $\mathbf{N}$ em milho}

Para identificar os possíveis genes envolvidos na assimilação do $\mathrm{N}$ em milho foram realizadas buscas por meio do BLAST no Banco de Dados do Genoma de Milho utilizando sequências já identificadas das enzimas NRT, NR, NRiT, NRi, GS, GOGAT e GDH identificados nas plantas modelo $A$. thaliana e $O$. sativa. Foram identificados 26 putativos genes que possivelmente participam da assimilação do nitrogênio (Tabela 1). Destes, 12 codificam as enzimas NR (quatro genes) e NRT (oito genes) que participam da primeira etapa da assimilação do nitrogênio transformando $\mathrm{NO}_{3}{ }^{-}$em $\mathrm{NO}_{2}{ }^{-}$realizada pela enzima nitrato redutase, e pela nitrato redutase transporte que participa do transporte de ni- trato do solo ao citossol da raiz ou folha. Foi identificado um gene que participa da transformação do nitrito em amônia e um gene que participa do transporte do nitrito, codificados pelas enzimas NRi e NRiT, respectivamente. Foram identificados seis genes GS responsáveis pela assimilação do nitrato gerado no metabolismo da alontoína e da aspargina, quatro genes GOGAT que utilizam a glutamina para sintetizar aminoácidos e dois genes da enzima GDH que operam quando a concentração de $\mathrm{NH}_{4}^{+}$está acima de $1,5 \mathrm{mM}$ entretanto se a concentração de $\mathrm{NH}_{4}{ }^{+}$for abaixo desse valor, uma rota metabólica alternativa GOGAT é ativada (CEREZO et al., 2001).

O número de genes envolvidos na assimilação do $\mathrm{N}$ em milho (26) foi menor quando comparado com arabidopsis (77) e maior que arroz (23). A distribuição desses genes em diferentes espécies do reino vegetal indica que esses genes são bastante conservados e apresentam funções importantes ligados ao desenvolvimento e à nutrição mineral em plantas. De modo geral, o número de genes das espécies monocotiledôneas (arroz e milho) não diferiram muito uma da outra, apesar do genoma do milho ser muito maior (2500 $\mathrm{Mpb}$ ) comparado com arroz (430 Mbp) e arabidopsis (145 $\mathrm{Mbp}$ ). As diferenças encontradas em milho, em comparação ao arroz e arabidopsis podem ser parcialmente explicadas por eventos de duplicação de genes e/ou perda de genes durante o processo de evolução do genoma de milho, que pode ter contribuído para a diminuição ou o aumento no número de genes envolvidos na assimilação do nitrogênio (BUCHNER; HAWKESFORD, 2014). Além do mais, os genomas diferem quanto ao nível de ploidia e número de cromossomos entre as espécies.

Tabela 1: Comparação do número de sequências encontradas de cada enzima relacionadas à assimilação do nitrogênio em arabidopsis (Arabidopsis thaliana), arroz (Oryza sativa) e milho (Zea mays).

\begin{tabular}{lccc}
\hline \multicolumn{1}{c}{ Enzima } & $\begin{array}{c}\text { Arabidopsis } \\
\text { thaliana }\end{array}$ & $\begin{array}{c}\text { Oryza } \\
\text { sativa }\end{array}$ & $\begin{array}{c}\text { Zea } \\
\text { mays }\end{array}$ \\
\hline $\begin{array}{l}\text { Nitrato Redutase (NR) } \\
\begin{array}{l}\text { Nitrato de Transporte } \\
\text { (NRT) }\end{array}\end{array}$ & 2 & 4 & 4 \\
$\begin{array}{l}\text { Nitrito Redutase (NRi) } \\
\begin{array}{l}\text { Nitrito de transporte } \\
\text { (NRiT) }\end{array}\end{array}$ & 1 & 7 & 8 \\
$\begin{array}{l}\text { Glutamina Sintetase (GS) } \\
\text { Glatamato Sintase } \\
\text { (GOGAT) }\end{array}$ & 7 & 1 & 1 \\
$\begin{array}{l}\text { Glutamato Desidrogenase } \\
\text { (GDH) }\end{array}$ & 3 & 3 & 6 \\
\hline Total & 77 & 3 & 2 \\
\hline
\end{tabular}

Os genes que codificam as diferentes enzimas envolvidos na assimilação de nitrogênio estão divididas em cinco grupos principais, uma vez que possuem funções e características distintas (Figura 1). A análise mostrou similaridades dentre as relações filogenéticas e função das diferentes enzimas envolvidas na assimilação do nitrogênio. As sequências dos genes que codificam as enzimas de transporte (NRT e NRiT) encontram-se agrupadas em um mesmo grupo (Fi- 
gura 1), o que pode ser atribuído ao fato de que esses genes possuem funções semelhantes. Essas enzimas são responsáveis pela absorção do nitrato pelas raízes ou sua translocação na planta (TSAY et al., 2007). Em arabidopsis, os genes que codificam as NRT é constituída por duas famílias, NRT1 e NRT2 que possuem 53 e sete membros, respectivamente. As NRT1.1, NRT1.2, NRT2.1, NRT2.2 e NRT 2.4 participam diretamente da absorção de nitrato em arabidopsis, utilizando o gradiente de elétrons para o transporte do solo para o interior das células vegetais (KROUK et al., 2010).

Para lidar com concentrações variadas de nitrato nos solos, as raízes das plantas desenvolveram, pelo menos, três sistemas de absorção de nitrato, dois sistemas de transporte de alta afinidade (HATS) e um sistema de baixa afinidade de transporte (LATS), responsável pela aquisição de nitrato (CRAWFORD; GLASS, 1998). Os genes da família NRT1 codificam um transportador de baixa afinidade, exceto NRT1.1 que codifica um transportador tanto de baixa e como de alta afinidade. Já os genes que da família NRT2 codifi- cam transportadores de alta afinidade (LIU; HUANG; TSAY, 1999). Para Crawford e Glass (1998) a estruturação dessas duas famílias NRT1 e NRT2, alta e baixa afinidade, respectivamente, deve-se a replicação dos genes e sua posterior divergência. Entretanto, em milho, não foi encontrado nenhum gene que codifica a família NRT2. Isso pode ter ocorrido durante o processo evolutivo, onde o ganho dessa família pode ter sido posterior ao processo de diversificação entre mono e dicotiledôneas. No mesmo grupo, encontram-se os genes que codificam a enzima de transporte de nitrito em arabidopsis, milho e arroz. O gene que codifica NRiT foi descrita inicialmente em cloroplastos das algas verdes (Chlamydomonas). Liseron-Monfins et al. (2013) identificaram pela primeira vez em milho um único gene que codifica a NRiT. Em pepino (Cucumis sativus. L.) a NRiT identificada está localizada na membrana interna do cloroplasto, cuja função é carregar o nitrito a partir do citoplasma para dentro do estroma do cloroplasto durante a assimilação do nitrato (SUGIURA; GEORGESCU; TAKAHASHI, 2007).

Figura 1: Análise filogenética das 81 sequências protéicas das enzimas envolvidas no ciclo do nitrogênio obtidas a partir de A. thaliana, O. sativa (ORZNR - gi|27527625|, ORZNRi - gi|573920733|, ORZGS - gi|22748337|, ORZGOGAT - gi|4008156|, ORZGDH - gi|33242905|) e Z. mays (ZmNRT1.1-GRMZM2G327050, ZmNRT1.2-GRMZM2G085411, ZmNRT1.3-GRMZM2G137421, ZmNRT1.4-GRMZM2G347457, ZmNRT1.5-GRMZM5G821252, ZmNRT1.6-GRMZM2G043926, ZmNRT1.7-GRMZM2G104542, ZmNRT1.8-GRMZM2G085411, ZmNR.1-GRMZM2G568636, ZmNR.2-GRMZM2G428027, ZmNR.3-GRMZM5G878558, ZmNR.4-GRMZM2G076723, ZmNRi.1-GRMZM2G090338), ZmNRiT.1(GRMZM5G827496, ZmGS.1-GRMZM5G872068, ZmGS.2-GRMZM2G046601, ZmGS.3-GRMZM2G098290, ZmGS.4-GRMZM2G024104,ZmGS.5-GRMZM2G036464,ZmGS.6-GRMZM2G050514,ZmGOGAT.1-GRMZM2G077054, ZmGOGAT.2-GRMZM2G085078, ZmGOGAT.3-GRMZM2G375064, ZmGOGAT.4-GRMZM2G036609, ZmGDH.1-GRMZM2G159544, ZmGDH.2-GRMZM2G427097). A árvore filogenética foi construída com o programa MEGA 6.0 utilizando o método NJ.

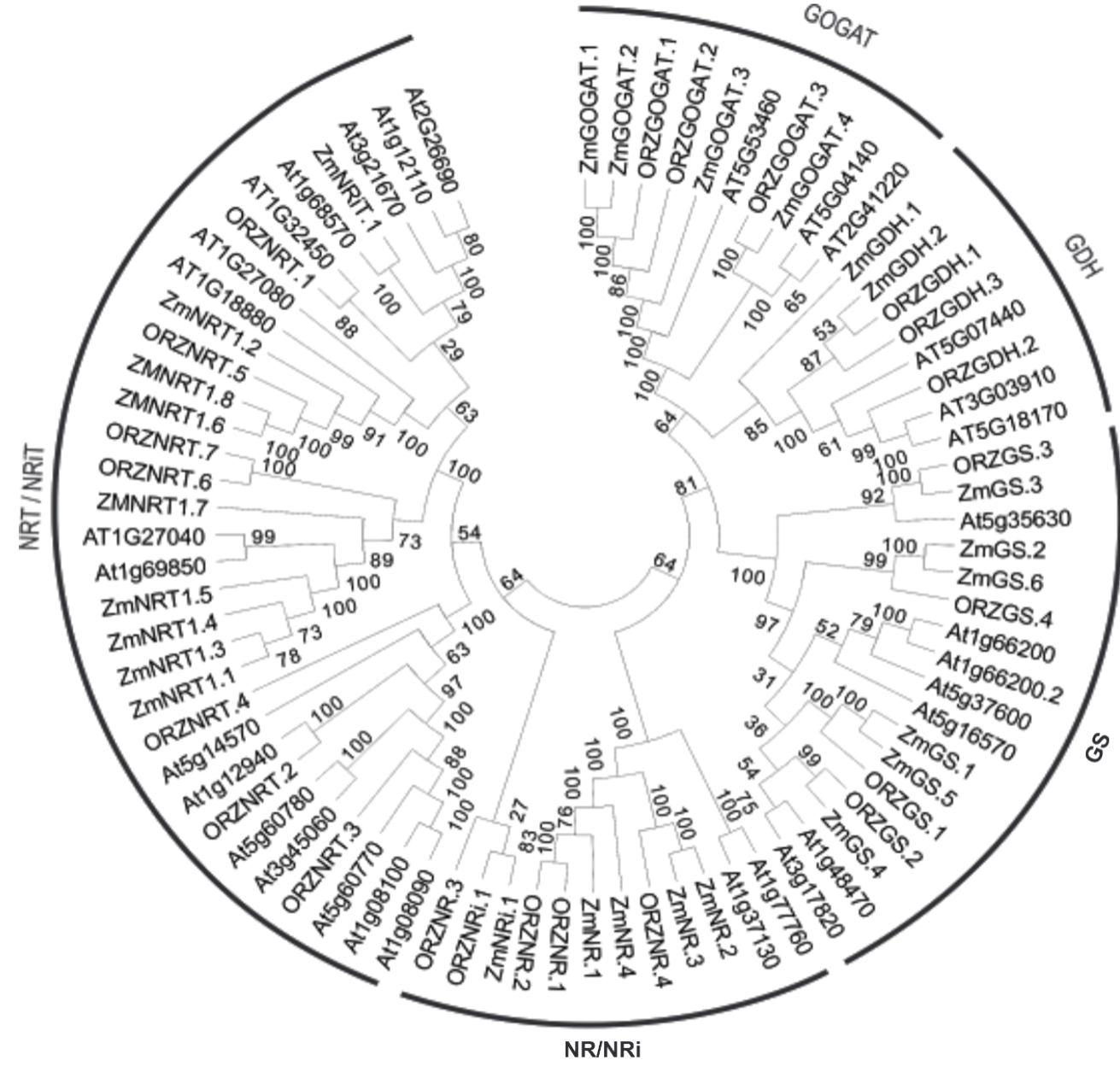


Em outro grupo, encontram-se as enzimas NR e NRi. Os genes que codificam as enzimas NRs são responsáveis por transformar o nitrato em nitrito. As NRs de Arabidopsis, milho e arroz se encontram-se no mesmo clado. $\mathrm{O}$ mesmo é observado para as NRis, no qual as NRis de monocotiledôneas se agruparam no mesmo clado. A função dessa enzima é transformar o nitrito em amônio. Por apresentarem funções e características semelhantes elas encontram-se no mesmo grupo (Figura 1). Em grupos distintos encontram-se os genes que codificam as enzimas GS e GOGAT, que são encontradas dentro do cloroplasto e assimilam o amônio e o transforma em aminoácidos, glutamina e glutamato que servem de substrato para a produção de todos os outros aminoácidos necessários para a síntese de proteínas (CAMARGOS; AGUIAR; AZEVEDO, 2006). Segundo Unno et al. (2006) a baixa atividade dessas enzimas impede que as plantas atinjam seu máximo em potencial produtivo, pois é considerada processo chave na incorporação de N. Em outro grupo encontram-se os genes que codificam a enzima GDH, cuja função é incorporar os íons de amônio em glutamato na presença de NADP $(\mathrm{H})$ como cofator (TERCÉ-LAFORGUE et al., 2004). Entretanto o papel fisiológico dessa enzima ainda é controverso. De acordo com Skopelitis et al. (2006) sob estresse salino quem assimila o amônio é a GDH, e não mais a GS/GOGAT principal via de assimilação. A sua expressão aumenta devido aos altos níveis de amônio, o que faz com ela exerça um papel de desintoxicação na planta (ZHOU et al., 2015). O número de genes de cada enzima variou entre as diferentes espécies. Essas diferenças podem ser atribuídas às adaptações evolutivas e às mudanças ambientais ao longo dos anos, o que pode ter levado a perdas e/ou ganhos de genes que podem ter funções específicas no metabolismo do nitrogênio entre as diferentes espécies vegetais.

A diversidade estrutural fornece evidências adicionais aos agrupamentos filogenéticos, além de informações evolutivas das famílias multigênicas, no qual o ganho ou perda de um exon/íntron pode ser causada por rearranjos e/ou fusões de diferentes porções dos cromossomos (WANG et al., 2014). O padrão de distribuição dos íntrons/exons dos genes que fazem parte da assimilação de $\mathrm{N}$ em milho é mostrado na Figura 2. O tamanho e a posição dos íntrons e exons mostram uma distribuição variável entre os diferentes grupos de genes das enzimas. Das 26 sequências de milho, três sequências (ZmNRT1.1, ZmNRT1.4 e ZmNRT1.5) não apresentaram íntrons. Nas demais sequências o número de introns dos genes variou de um (ZmNRT1.2) a 32 (ZmGOGAT.4) íntrons (Figura 2). Foi observado que os membros mais estreitamente relacionados de um mesmo grupo de genes, de modo geral, mostraram o mesmo padrão na estrutura exon/íntron, como número, posição e tamanho do íntron (Figura 2). Esse padrão de similaridade pode ser consequência de uma série de eventos de duplicação, mostrando conservação evolutiva dos genes que codificam as diferentes enzimas da assimilação de $\mathrm{N}$ em Z. mays.

Figura 2: Estrutura dos genes ZmNRT, ZmNRi, ZmNRiT, ZmGS, ZmGOGAT e ZmGDH em Z. mays. Os Íntrons estão representados pelas linhas em cinza e os exons em amarelo.

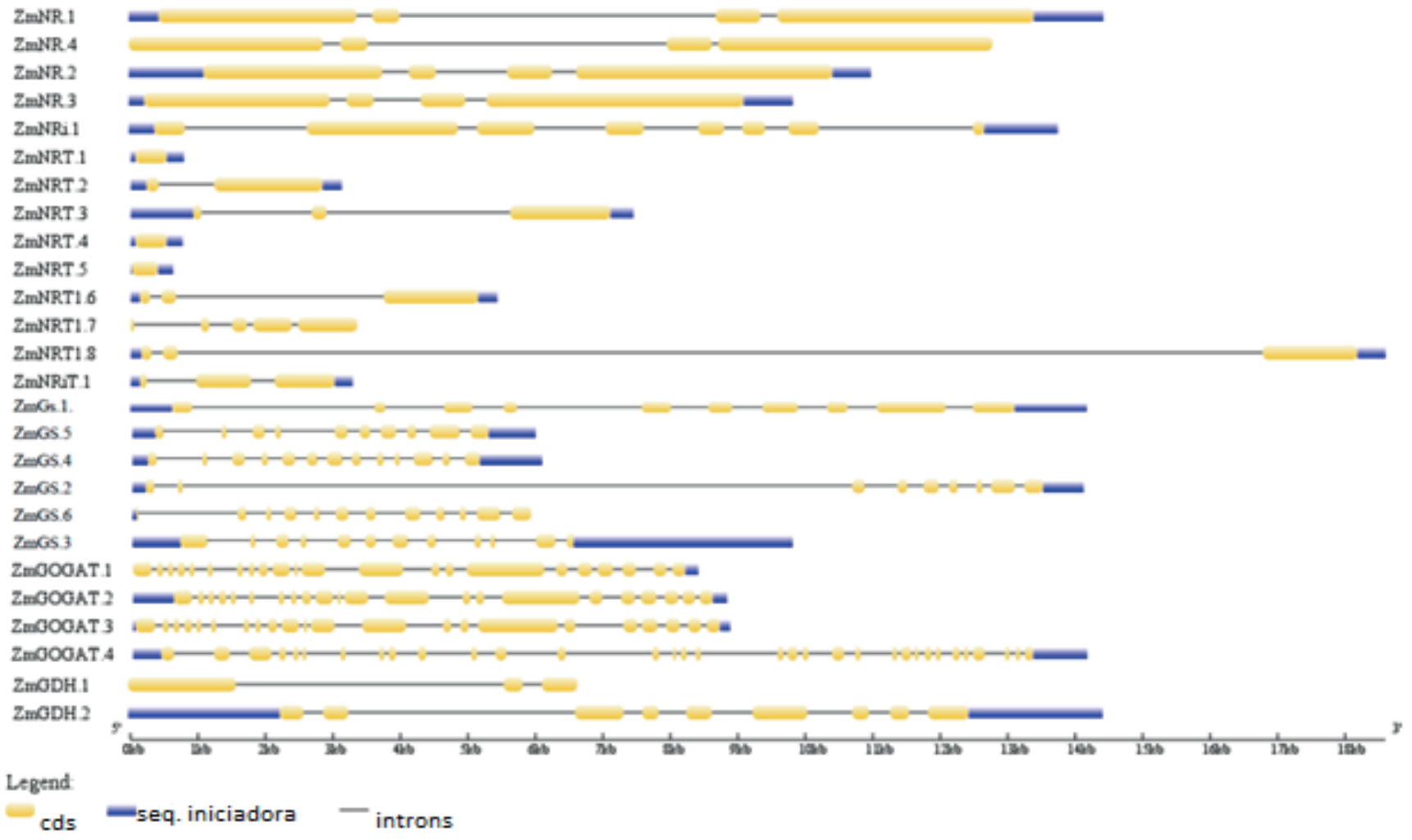




\section{Domínios conservados}

De modo geral os domínios funcionais são frequentemente conservados entre os genes de um mesmo grupo, compartilham as mesmas funções e provavelmente possuem um descendente em comum. Foi observado nas sequências que codificam a enzima nitrato redutase, $Z m N R .1$ a 3, a presença de três domínios (Figura 3). O domínio molibdopterina (Molybdopterin_EUK) possui 35 aminoácidos, cuja característica comum entre todos os membros que possuem esse domínio de ligação é possuir um co-fator pterina e parte da coordenação do metal molibdênio (Mo) é ligado a proteína cisteína que catalisa a transferência de um átomo de oxigênio (CAMPBELL, 1999). O molibdênio realiza papel fundamental como centro ativo da enzima, onde atua em processos como: desintoxicação de enxofre, assimilação do nitrato e a síntese de fito-hormônios em plantas (MENDEL, 2013). O molibdênio é um elemento essencial para os organismos em pequenas quantidades, no entanto, se indisponível é letal para a planta (MENDEL, 2013). O segundo domínio é a ferrodoxina redutase (FAD_FR-ferrodoxin reductase) com 112 aminoácidos. Essa proteína de ligação catalisa a transferência de elétrons da ferrodoxina reduzida a proteína ferro-enxofre para $\mathrm{NADP}^{+}$como a etapa final do mecanismo de transporte de elétrons do fotossistema I da fotossíntese. $\mathrm{O}$ terceiro domínio o citocromo b5 (Cytochrome_B5_2) catalisa a redução de duas moléculas do citocromo b5, utilizando NADH como um doador de elétrons. O gene que codifica a enzima $Z m R N 2$, além dos três domínios mencionados, possui o domínio RNA polimerase II (RNA_POL_II Repeat) com seis aminoácidos, cuja função principal é transcrever genes codificantes de proteínas. $\mathrm{O}$ domínio encontrado na sequência ZmNRi.1 é o nitrito/sulfito (NIR_SIR) com 16 aminoácidos, o sulfito e nitrito redutase são vitais para a assimilação da biossíntese de enxofre e nitrogênio.

As sequências que codificam a enzima GS compostas por ZmGS1, 3, 4, 5 e 6 contém dois motivos conservados: a glutamina sintetase (GLNA_1) com 17 aminoácidos e glutamina sintetase (GLNA_ATP) com 16 aminoácidos, a função de ambas é catalisar a hidrólise de glutamina em ácido glutâmico e amônia. A sequência $Z m G S 2$ possui apenas um domínio glutamina sintetase (GLNA_1). As sequências ZmGOGAT 1 a 4 possuem o domínio glutamina amido transferase tipo II (Glutamine amido transferase type_2) variando de 399 a 404 aminoácidos. A função desse domínio é catalisar a remoção do grupo amoníaco a partir de glutamina e, em seguida, transferir este grupo para um substrato para formar um novo grupo carbono-nitrogênio (VAN DEL HUEVEL et al., 2003). O gene que codifica a enzima $Z m G D H 2$ possui um sítio ativo com 13 aminoácidos e o domínio Glutamato/Leucina/Fenilalanina/Valina desidrogenase (GLFV_Dehydrogenase) de 102 a aminoácidos, no qual sua função é catalisar o NAD- ou realizar a desaminação reversível NADP-dependentes de glutamato em $\alpha$-cetoglutarato. Por fim, a sequência ZmGDH1 não apresentou nenhum motivo. Essa enzima só é utilizada como rota alternativa geralmente em condições de estresse (MARCHI et al., 2014). As sequências de NRT e NRiT não apresentaram domínios conservados.

Figura 3: Distribuição dos motivos conservados da ZmNRT, ZmNRi, ZmNRiT, ZmGS, ZmGOGAT e ZmGDH em Z. mays. A posição e a ordem dos símbolos correspondem a real região conservada na sequência da proteína.
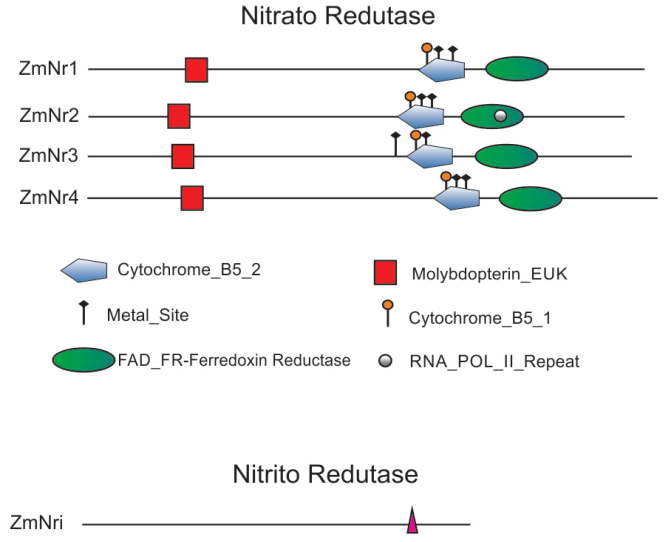

$\triangle$ NIR_SIR

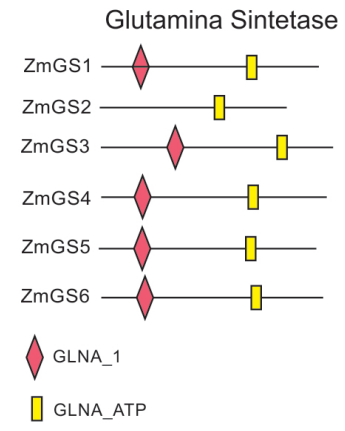

Glutamina Dehidrogenase

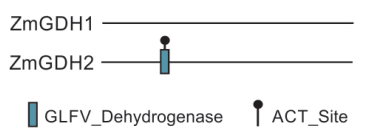

Glutamato Sintetase

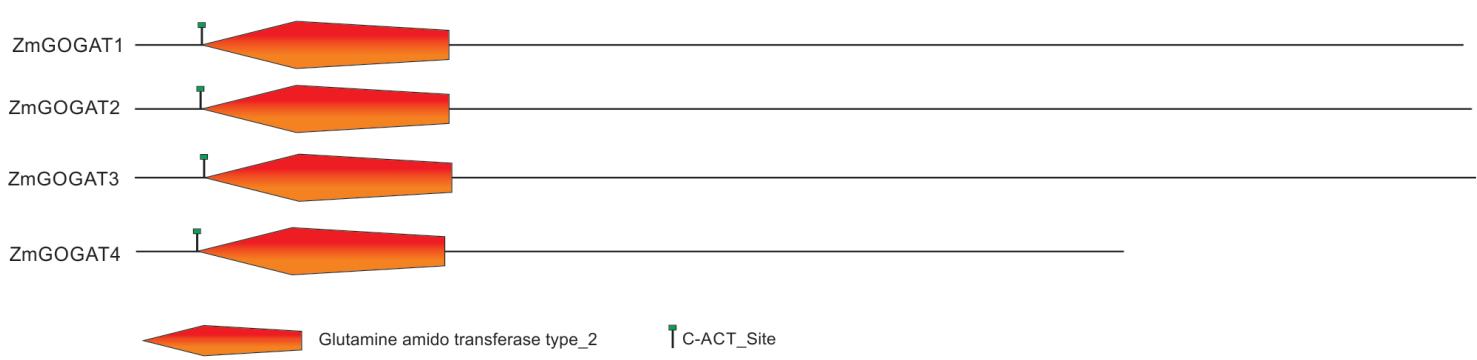




\section{Expressão de genes identificados no ciclo do $\mathrm{N}$ em milho}

Os padrões de expressão de genes pode fornecer pistas importantes sobre a função e localização que o gene pode exercer. Para analisar ainda mais a especificidade dos tecidos dos genes envolvidos na assimilação de $\mathrm{N}$ em milho, o perfil de expressão dos 26 genes foram analisados como mostrado na Figura 4. Foi observado a formação de dois grupos distintos quanto a expressão. No primeiro grupo está aqueles genes que foram poucos expressos na maioria dos tecidos e órgãos analisados, onde estão os genes ZmNRT7, ZmGDH2, ZmGS4, ZmGS1, ZmGS5, ZmGS3, ZmGOGAT1, ZmGOGAT4, ZmNRi e ZmGOGAT2. No segundo grupo estão aqueles genes que foram constitutivamente expresso em quase todos os tecidos e órgãos analisados, e mostraram níveis de expressão elevados, para os genes ZmGOGAT3, ZmNR3, ZmNR2, ZmNRT3, ZmNRT6, ZmNRT5, ZmNRT1, ZmNRT4, ZmGDH1, ZmNR1, ZmNR4, ZmNRiT, ZmNRT2,
ZmNRT8, ZmGS2 e ZmGS6. Os níveis de expressão para esses genes foram elevados nas bibliotecas associadas a tecidos de desenvolvimento da planta, o que indica que eles podem desempenhar um papel importante e são fundamentais para o desenvolvimento das plantas de milho. O nitrogênio é utilizado pelas plantas em várias etapas, incluindo absorção, assimilação, translocação, reciclagem e remobilização. Esses eventos são altamente dinâmicos e complexos, e inúmeros genes podem estar potencialmente envolvidos nesses processos. Os resultados encontrados neste trabalho são reforçados por Liseron-Monfils et al. (2013). Esses autores utilizaram sondas para analisar a expressão em diferentes tecidos de milho, onde foi observado a formação de quatro clusters cada um com características específicas, no entanto, todos relacionados a tecidos em desenvolvimento, corroborando com os dados encontrados nesse trabalho para o segundo grupo.

Figura 4: Perfil de expressão in silico dos genes ZmNRT, ZmNRi, ZmNRiT, ZmGS, ZmGOGAT e ZmGDH em Z. mays. Os números de 1 a 60 na parte inferior da figura indicam as bibliotecas/tecidos que esses genes se expressam. 1:24H_Semente em germinação; 2:6DAS_GH_Coleóptilo; 3:6DAS_GH_Raiz primária; 4:V1_Raiz primária; 5:VE_Semente inteira; 6:VE_Raiz primária; 7:V1_Mistura de folhas; 8:V1_Caule; 9:V4_Caule; 10:V3_Caule; 11:V3_Folha primária e bainha; 12:V3_Folha superior; 13:V5_Meristema apical; 14:V̄_ 5 _Primeiro Internó; 15:V5_Ápice foliar da $2^{\mathrm{a}}$ Folha; 16:V5_Base foliar da $2^{\overline{\mathrm{a}}}$ Folha; 17:V7_Primeiro Internó; 18:V7_Ápice foliar da 2 ${ }^{\mathrm{a}}$ Folha; 19:V7_Base foliar da 2 ${ }^{\mathrm{a}}$ Folha; 20:V9_4º_Internó; 21:V9_8 ${ }^{\mathrm{a}}$ Folha; 22:V9_11 ${ }^{\mathrm{a}}$ Folha; 23:V9_13 $3^{\mathrm{a}}$ Folha; 24:V9_Folhas imaturas; 25:V13_Pendão imaturo; 26:V18_Pendão meiótico; 27:V18_ Espiga imatura; 28:VT_ 13 ${ }^{\text {a }}$ Folha; 29:R1_Pré-polinização da espiga; 30:R1_Estilo-estigma (cabelo); 31:R1_Anteras; 32:R1_ Espiga; 33:R2 13 ${ }^{\mathrm{a}}$ Folha; 34:R2 Folha da espiga; 35:R2 Espiga; 36:2DAP Semente inteira; 37:4DAP Semente inteira; 38:6DAP_Semente inteira; 39:8DAP_Semente inteira; 40:10DAP_Semente inteira; 41:12DAP_Semente inteira, 2:12DAP_ Endosperma; 43:14DAP_Semente inteira; 44:14DAP_Endosperma; 45:16DAP_Semente inteira; 46:16DAP_Endosperma, 47:16DAP_Embrião; 48:18DAP_Semente inteira; 49:18DAP_Endosperma; 50:18DAP_Embrião; 51:18DĀP_Pericarpo; 52:20DAP_Semente inteira; 53:20DAP Endosperma; 54:20̄DAP Embrião; 55:22DAP Semente inteira; 56:22DAP Endosperma; 57:22DAP_Embrião; 58:24DAP_Semente inteira; 59:24̄DAP_Endosperma; 60:24DAP_Embrião. Os símbolos de cada uma das 60 bibliotecas correspondem ao estádio fenológico da cultura do milho.
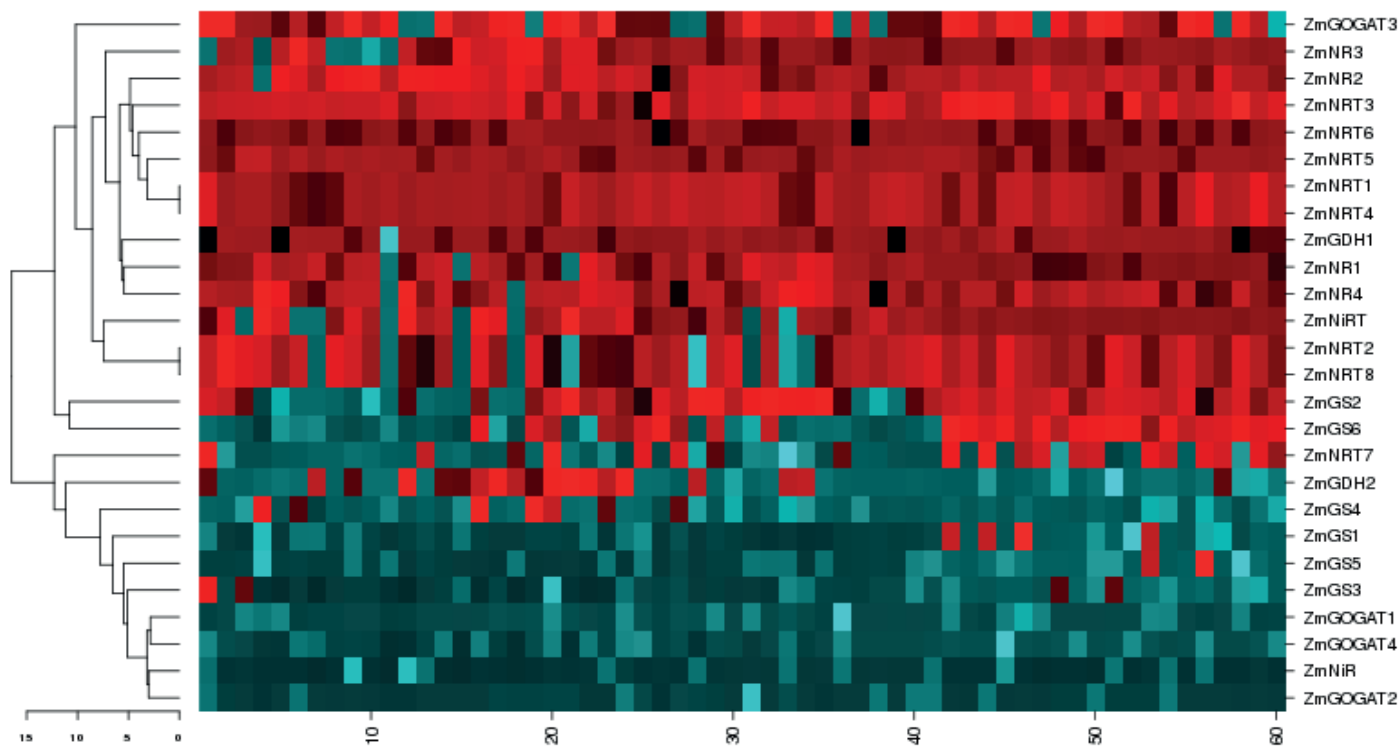

Euclidean distance

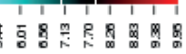




\section{Conclusão}

Este trabalho forneceu informações importantes na identificação e na caracterização dos diferentes genes que codificam as enzimas que estão envolvidas no metabolismo do nitrogênio em milho, onde foram identificados 26 genes: ZmNRT (seis), ZmNR (quatro), ZmNRiT (um), ZmNRi (um), $Z m G S$ (seis), ZmGOGAT (quatro) e ZmGDH (dois).

Os dados gerados neste trabalho forneceram subsídios para selecionar os melhores genes-candidatos para futuras análises funcionais, a serem utilizados nos programas de melhoramento de milho, que têm como objetivo aumentar a produtividade e a obtenção de um sistema agrícola mais sustentável devido ao eficiente uso do nitrogênio (NUE).

\section{Referências}

ANDRADE NETTO, J. F. A atividade da enzima redutase do nitrato e glutamina sintase em cafeeiro Arábica. Escola Superior de Agricultura Luiz de Queiroz, 2005. 60p. Dissertação (Mestrado em Fitotecnia) - Escola Superior de Agricultura Luiz de Queiroz (ESALQ-USP), Piracicaba, SP.

BREDEMEIER, C.; MUNDSTOCK, C. M. Regulação da absorção e assimilação do nitrogênio nas plantas. Ciência Rural, v. 30, n. 2, p. 365-372, 2000.

BUCHNER, P.; HAWKESFORD, M. J. Complex phylogeny and gene expression patterns of members of the Nitrate Transporter 1/Peptide Transporter Family (NPF) in wheat. Journal of Experimental Botany, v. 65, n. 19, p. 5697-5710, 2014.

CAMARGOS, L. S.; AGUIAR, L. F.; AZEVEDO, R. A. Changes of nitrate reduction in Jack bean (Canavalia ensiformis) changes from leaf to root during development. New Zealand Journal of Crop and Horticultural Science, v. 34, n. 2, p. 131-137, 2006

CAMPBELL, W. H. Nitrate reductase structure function and regulation on bridging to gap between biochemistry and physiology. Annual Review Plant Physiology Plant Molecular Biology, v. 50, p. 277-303, 1999.

CRAWFORD, N. M.; GLASS, A. D. M. Molecular and physiological aspects of nitrate uptake in plants. Trends Plant Science, n. 3, n. 10, p. 389-95, 1998.

CEREZO, M. et al. Major alterations of the regulation of root NO3- uptake are associated with mutation of Nrt2.1 and Nrt2.2 genes in Arabidopsis. Plant Physiology, v. 127, n. 1, p. $262-271,2001$.

CONAB. Companhia Nacional de Abastecimento. Disponível em: <http://www.conab.gov.br/>. Acesso em: 06 jul. 2016.

DEBOUBA, M.; DGUIMI, H.; GHORBEL, M. Expression pattern of genes encoding nitrate and ammonium assimilating enzymes in Arabidopsis thaliana exposed to short term $\mathrm{NaCl}$ stress. Journal of Plant Physiology, v.
170, n. 2, p. 155-60, 2013.

EPSTEIN, E.; BLOOM, A. J. Nutrição mineral de plantas: princípios e perspectivas. Londrina: Editora Planta, 2006. 403p.

HUANG, L. et al. HY5 regulates nitrite reductase 1 (NIR1) and ammonium transporter1;2 (AMT1;2) in Arabidopsis seedlings. Plant Science, v. 238, p. 330-339, 2015.

KROUK, G. et al. Nitrate-regulated auxin transport by NRT1.1 defines a mechanism for nutrient sensing in plants. Developmental Cell, v. 18, n. 6, p. 927-937, 2010.

LEA, P. J. Primary nitrogen metabolism. In: DEY, P. M. , HARBORNE, J. B. Plant biochemistry. Academic, 1997. p. 273-313.

LISERON-MONFILS, C. et al. Nitrogen transporter and assimilation genes exhibit developmental stage-selective expression in maize (Zea mays L.) associated with distinct cis-acting promoter motifs. Plant Signaling \& Behavior, v. 8, n. 10, p. e260561-14, 2013.

LIU, K. -H.; HUANG, C. Y.; TSAY, Y. F. CHL1 is a dual affinity nitrate transporter of Arabidopsis involved in multiple phases of nitrate uptake. Plant Cell, v. 11, n. 5, p. 865-874, 1999.

MARCHI, L. et al. Glutamate dehydrogenase isoenzyme 3 (GDH3) of Arabidopsis thaliana is less thermos table than GDH1 and GDH2 isoenzymes. Plant Physiology and Biochemistry, v. 83, p. 225-231, 2014.

MENDEL, R. R. The molybdenum cofactor. The Journal of Biological Chemistry, v. 288, n. 19, p. 13165-13172, 2013.

SILVEIRA; J. A. G. et al. Salt-induced decrease in nitrate uptake and assimilation in cowpea plants. Brazilian Journal of Plant Physiology, v. 11, n. 2, p. 77-82, 1999.

SKOPELITIS, D. S. et al. Abiotic stress generates ROS that signal expression of anionic glutamate dehydrogenases to form glutamate for proline synthesis in tobacco and grapevine. The Plant Cell, v. 18, n. 10, p. 2767-2781, 2006.

SUGIURA, M.; GEORGESCU, M. N.; TAKAHASHI, M. A nitrite transporter associated with nitrite uptake by higher plant chloroplasts. Plant Cell Physiology, v. 48, n. 7, p. 1022-1035, 2007.

TERCÉ-LAFORGUE, T. et al. Glutamate dehydrogenase of tobacco is mainly induced in the cytosol of phloem companion cells when ammonia is provided either externally or released during photorespiration. Plant Physiology, v. 136, n. 4, p. 4308-4317, 2004.

TSAY, Y. F. et al. Nitrate transporter and peptide transportes. FEBS Letters, v. 581, n. 12, p. 2290-2300, 2007. 
UNNO, H. et al. Atomic structure of plant glutamine synthetase. The Journal of Biological Chemistry, v. 281, n. 39, p. 29287-29296, 2006.

VAN DEN HEUVEL, R. H. et al. The active conformation of glutamate synthase and its binding to ferredoxin. Journal of Molecular Biology, v. 330, n. 1, p. 113-128, 2003.

WANG, R. et al. Genomic analysis of the nitrate response using a nitrate reductase-null mutant of Arabidopsis. Plant Physiology, n. 136, n. 1, p. 2512-522, 2004.

WANG, W.; VINOCUR, B.; ALTMAN, A. Plant responses to drought, salinity and extreme temperatures: towards genetic engineering for stress tolerance. Planta, v. 218, n. 1, p. 1-14, 2003.

WANG, L. et al. Genome-wide identification of WRKY family genes and their response to cold stress in Vitis vinifera. BMC Plant Biology, v. 14, n. 103, p. 1-14, 2014.

ZHOU, Y. et al. Over-expression of a glutamate dehydrogenase gene, MgGDH, from Magna porthegrisea confers tolerance to dehydration stress in transgenic rice.

Planta, v. 241, n. 3, p. 727-740, 2015.

Recebido em: 20.11.2016

Aceito em: 26.12.2016 